\title{
Factors influencing management of human papilloma virus: case report of a young Mexican woman
}

\begin{abstract}
Purpose: Human papilloma virus infection is one of the most common sexually transmitted infections worldwide. An understanding of psychosocial and situational factors that influence women who have Human papilloma virus to use protective behavior is important for implementation of strategies contributing to consistent use of protective behaviors and timely diagnosis and treatment for those with Human papilloma virus infection.
\end{abstract}

Methods: A case study is presented, exemplifying the multitude of psychosocial, cultural and situational factors potentially impacting health promotion behaviors among Mexican women.

Results: Being a carrier of Human papilloma virus infection affects women emotionally and impacts interpersonal and sexual relationships thus identifying importance of these factors for Human papilloma virus management. Multiple personal and situational factors strongly influence Human papilloma virus management including knowledge about Human papilloma virus infection, communication with sexual partners and importantly the presence of machismo.

Conclusion: Human papilloma virus infection impacts women's health worldwide with variation in management of psychosocial and situational clinical dilemmas according to national and institutional health standards.

Keywords: human papilloma virus, carrier woman, management, sexual relationship
Volume 4 Issue I - 2017

\author{
Gloria Maricela Guerra Rodríguez,' Jane \\ Dimmitt Champion, ${ }^{2}$ María Guadalupe \\ Moreno Monsiváis, ${ }^{3}$ Octavio Augusto \\ Olivares Ornelas,' Héctor Manuel Gil \\ Vázquez' \\ 'Universidad Autónoma de Tamaulipas, Mexico \\ ${ }^{2}$ School of Nursing, The University of Texas at Austin, USA \\ ${ }^{3}$ Universidad Autónoma de Nuevo León, Mexico
}

\begin{abstract}
Correspondence: Gloria Maricela Guerra Rodríguez, Universidad Autónoma de Tamaulipas, México, Tel 868। 2905 0I, Email gguerra@uat.edu.mx
\end{abstract}

Received: August 09, 2017| Published: October 10, 2017
Abbreviations: STI, sexually transmitted infection; HPV, human papillomavirus; USPSTF, united states preventive services task force

\section{Introduction}

Many individuals contract a sexually transmitted infection (STI) at some point in their lives. This is particularly true among women, in part as a result of their vulnerability related to biological, psychological and situational characteristics. Human papillomavirus (HPV) is one of the most common STIs among women with over 290 million women infected. ${ }^{1}$ HPV outcomes include high morbidity and mortality. Annually, HPV causes 530,000 cases of cervical carcinoma and 275,000 deaths from this virus. ${ }^{2}$

HPV consists of at least 100 different types, including more than 30 genital strains that can be transmitted sexually, of which two types of HPV can cause infections of the skin or mucosal tissue of the genital area such as the cervix, vulva, mouth, vagina or anus where usually no clinical symptoms with the risk of leading to genital warts, and others, invasive cervical cancer. ${ }^{3}$ Because HPV is often asymptomatic, many people are unaware of their infection status and its ability to transmit the virus to a sexual partner. Individuals may as a result, engage in high risk sexual behavior. HPV is so common in today's society that more than $50 \%$ of sexually active women and men get it at some point in their lives. ${ }^{4}$ It has been estimated that approximately $75 \%$ of women who are sexually active will be diagnosed with HPV during their lifetime. ${ }^{5}$ Therefore, control of HPV in this population requires the development of strategies for primary (condom use and vaccination) and secondary (diagnosis and treatment) prevention, self-care, identification of high risk sexual relationships, situations or vulnerability and encouragement of health promotion including adoption of preventive measures. ${ }^{6}$

The incidence and mortality rates for cervical cancer within industrialized countries have decreased significantly over the past 50 years due to the implementation and use of the Pap test. ${ }^{7}$ This test has been found to be an effective tool for early detection of cervical neoplasia and development of cervical cancer primarily caused by HPV. Early detection and proper follow-up increases the probability of cervical cancer survival to almost $100 \%{ }^{8}$ Unfortunately, despite the fact that the health sector offers services for early detection of cervical cancer, a lack of HPV knowledge, specifically in most cases where there are no signs or symptoms, delays its detection and treatment. ${ }^{9}$

The public and private health sectors are responsible for disseminating information among young women concerning the importance of the implementation of the HPV vaccine. The most common HPV vaccine used at this time in Mexico protects against two types of high risk HPV associated with precursor cervical lesions (16 and 18), and the two types of low-risk HPV (6 and 11) associated with the presence of genital warts. Considering the limited protection offered by vaccination, there is a need to educate women who have been vaccinated as well as those who have not, concerning periodic cytological examination in order to reduce future rates of cervical cancer mortality and morbidity. ${ }^{10}$

The Advisory Committee on Immunization Practices ${ }^{11}$ recommended routine HPV vaccination for girls 11 and 12 years of age, with the recommendation to start the series in young women of 13-26 years of age who have not started or completed the vaccine series of three doses. In 2011, the Advisory Committee on Immunization Practices recommended routine quadrivalent HPV vaccination for all 
young men 11 to 21 years of age. The vaccine is also recommended for men 22-26 years of age and in certain subgroups.

Treatment of sexual partners is necessary to interrupt the transmission of STI. This must be achieved through identification of carriers via health services however is difficult as barriers to effectiveness treatment, particularly for women include the need to notify their partners ${ }^{6}$ Unfortunately, it may not seem as important to a man to know whether or not they have HPV at some point in life as compared to women for whom it is very important due to the higher risk of cervical cancer. ${ }^{12}$

The importance and meaning that contracting HPV has for an individual is related to one's knowledge about the virus. Evidence indicates that both men and women tend to have erroneous information about transmission of STI including HPV. Men often do not understand that men can transmit the virus and that it can lead to cervical cancer in women. Men also know little about the possible consequences of HPV infection for both women and men. This limited knowledge is a barrier to the use of barrier methods for prevention and also acquisition of the HPV vaccine.

Woman who have HPV have many factors to consider when deciding whether or not to engage in protective behaviors. It is important to consider the emotional aspect as women may have feelings of guilt related specifically to the stigma of HPV. Negative psychosocial effects of stigma include guilt, shame, isolation, fear and denial after a diagnosis, indicating a concern about both the social and physical impacts of STI. ${ }^{13-15}$ Men who are informed via testing that they are HPV positive may assume this is evidence of a partner "cheating" or involving multiple partner sexual relationships. This reaction has been attributed to machismo among men and women. Machismo may inhibit disclosure of a HPV diagnosis due to fears of being labeled as promiscuous or non-monogamous. Machismo is related to ideation concerning illness and infidelity thereby increasing infection risk, creating obstacles to partner notification and treatment for self and partner, as well as adaptation of protective behavior. ${ }^{16-18}$

A HPV diagnosis can negatively impact an intimate relationship. Waller et al. ${ }^{19}$ found women living with HPV reported a number of psychological problems associated with intimate relationship, including lack of social support, fear of disclosure and rejection, fertility and transmission concerns and sexual problems. While it is important to note these issues are important to address, there is particular concern given its potential impact on HPV persistence and progression. Research concerning the etiology of cervical cancer is suggestive of an association between psychosocial factors such as depression, anxiety, social support and cancer pathogenesis. ${ }^{20}$ Cervical cancer is preventable. It is as responsibility of health care providers to provide patients with accurate HPV education ${ }^{21}$ addressing psychological and emotional aspects that may directly or indirectly influence their sexual behavior.

Family environment and socio-cultural factors influence sexual behavior. Historically, within Mexico, courtship was controlled by parents and premarital sex was condemned. ${ }^{22}$ These cultural perspective are still present within families in Mexico but are changing. Studies identify sexual activity at an early age while the need for a virgin-to-marriage appearance is lessened. This situation favors multiple sexual partner relationships, increased frequency of sharing of sexual partners, and the possibility that condoms are not routinely used. These evolving changes in the family environment and socio-cultural context of sexual behavior in Mexico potentially increases the risk of contracting a STI such as HPV. ${ }^{6,23}$ The following case study about a young Mexican woman provides the context of family environment and socio-cultural factors influencing diagnosis and management of HPV in Mexico.

\section{Case presentation}

This case has had identifying details changed to maintain anonymity. The following case study presents the situation of a 19 year old Mexican woman attending college. For this case study the pseudonym Ms. J will be used. Ms. J had no previous history of chronic diseases or STI. She did not report high risk behaviors such as excessive alcohol use; and typically limited alcohol intake to approximately 2 drinks at social events. She also did not report any tobacco or substance use.

Discussion of this case begins with Ms. J seeking guidance and support from her professor after she learned of positive high-risk HPV test results. The test for high risk HPV was conducted at the clinic site in the college. Coincidently, Ms.J. was invited to have the exam at the public health clinic since she was conducting her clinics at the site and at the end of the day there happened to be an unused reagent available the clinic did not want to waste. Although she was asymptomatic, given this circumstance, Ms. J took the exam.

Ms. J had become sexually active within the past year and reported using different pregnancy prevention methods (e.g., morning after pill withdrawal) including sporadic use of condoms. She did not consider the use of condoms for STI prevention. During the search for support and initial guidance in fencing with her teacher coordinator of a preventive program for sexual education at the university where she studied, Ms. J revealed that the previous day had been told that her laboratory results were positive for HPV high risk. Mrs. J was tearful and revealed guilty feelings for failing as a daughter because she was sexually active and realized that this was against family culture. Ms. $\mathrm{J}$ said her greatest fear was the possibility of developing and dying of cervical cancer.

Ms. J expressed sorrow for having to seek help and was crying uncontrollably while asking why this had happened? She did not understand how she could have HPV because her current boyfriend was her first partner. She wondered how she had gotten the STI. Ms. $\mathrm{J}$ thought that possibly her boyfriend had other partners and that this was how he had gotten HPV. She felt, therefore, as if she had been deceived, since she believed that they had a monogamous relationship. Despite these feelings, Ms. J expressed an interest in understanding more about HPV. Ms. J's agrees to participate in the research work of her teacher to follow up on her diagnosis. By signing an informed consent voluntarily to be part of this research work with the objective of knowing which are the factors that influence women carrying HPV carry a protective behavior and avoid developing $\mathrm{Ca}$ CU.

The present study complied with the provisions of the General Health Law on Health Research, which establishes that for the development of health research, ethical aspects must be considered to ensure the dignity and well-being of individuals. She was prepared to seek treatment and share information about HPV with her partner to prevent cervical cancer. According to Ms. J's guidance from her teacher, she sought timely treatment that helped dispel her fears, fatalistic thoughts, and anxiety stemming in part from her lack of knowledge about HPV and cervical cancer. 
Ms. J sought treatment expedited by this anguish and concern regarding the HPV results. On physical exam, Ms. J had clinical evidence of genital warts in her perineal area. She had not identified any signs or symptoms and expressed confusion and fear regarding this finding. Following review of her laboratory results, the gynecologist elected to perform cervical cytology for an intraepithelial lesion. A colposcopy was performed identifying an atypical transformation zone described as an intraepithelial lesion grade I (acetowhite epithelium occupies $10 \%$ ). Laboratory results were not positive for HPV 16 or 18 however were positive for 31,3537 . The decision was made to perform electro-surgery in the transformation zone and endocervical area. Ms.J agreed to continue follow-up evaluations with repeat pap-smear testing. Of interest, Ms. J had received the first HPV (Gardasil) vaccine however did not complete the series.

Ms. J elected not to disclose her information about HPV to her family for fear of rejection. Ms. J said. "No puedo decir a mi Madre que tengo esta enfermedad porque se desilusionará de mi por no haber seguido las normas religiosas y llegar virgen al matrimonio. Besides, "Mama no sabe de mi relación con mi novio, no lo sabe porque no lo aceptaría porque él es mayor que yo (I can't tell my mother that I have this disease because she will be disappointed in my failure to follow religious rules and be a virgin at marriage. Besides, Mama does not know of my relationship with my boyfriend because she would not accept him because he is older than me)." Moreover, on previous occasions, "mi Madre lo ha visto bajo efectos del alcohol con conductas no apropiadas (my Mother has seen him under the influence of alcohol with inappropriate behaviors)." Ms. J's mother did not believe that a man who drinks would be a good man for her. Ms. J did decide however to discuss the situation with her partner. Ms. J's partner initially reacted with fear because of what little he knew about HPV. However, he offered support and apologized for causing her to have HPV. He expressed understanding that he was the one who transmitted HPV. He admitted to having multiple sexual partners without protection from STI or pregnancy. Although experiencing initial support from her partner, Ms. J continued to experience fear and uncertainty, not knowing whether it was right to tell others about her situation. She was worried that if other knew, they would label her as a "dirty woman" at risk for transmitting HPV to others.

Ultimately, Ms. J did tell one of her friends about having HPV. Unfortunately one of Ms. J's friends, for lack of knowledge about HPV decided to no longer associate with her. Ms. J's friend thought that she was a bad influence because she had HPV. Ms. J's other friends have fortunately provided emotional and financial support to comply with HPV management. Ms. J has received on-going support and counseling from her professor during the following months. Ms. J states that since learning about HPV. Her relationship with her boyfriend has changed. She feels rejected by her boyfriend both physically and emotionally. Ms. J recalls that at the beginning he expressed guilt and was calm and willing to support her, but since the initial HPV diagnosis he has been reluctant to use condoms or have STI check-ups. In this regard J says: "Mi novio me ha apoyado hasta hoy pero solo en aspecto económico para el seguimiento de mi tratamiento, pero me siento vacía y triste porque siento que solo está conmigo por lastima", "Creo que las cosas no van a funcionar y nos vamos separar (My boyfriend has supported me until today but only as concerns the economic aspect for the monitoring of my treatment. I feel empty and sad because I feel that it is only out of pity that he is with me, I think that things will not work out and we will separate)."
Despite this, Ms. J has realized that with protective measures she can prevent the development of cervical cancer. Ms. J has decided to commit to using STI protection, "Me siento total mente capaz de pedirle que usemos el condón y si no quiere ponérselo entonces yo no voy a querer (I feel totally capable of asking about and using condoms and if you don't want to put it on then I'm not going to want to have sex)." Ms. J indicated that one of the reasons why she did not consistently use STI protection or condoms was because of the trust and love she had for her partner. She was primarily interested in preventing pregnancy and trusted that he would take care of her. The gynecologist recommended cytological and colposcopic examination every four months the first year. During the second year, should all of Ms. J's clinical or cytological evaluations be negative, she will continue with testing every six months. With respect to sexual relationships, the gynecologist emphatically recommended condom use with her partner and instructed her partner to seek urological evaluation.

\section{Discussion}

This case study exemplifies unintended consequences of inadequate knowledge about HPV, its prevention and treatment. A lack of knowledge is reflected in this case as although an understanding of HPV was present, the individual did not know where to seek professional consultation. She experienced anguish and fear concerning her diagnosis leading to fatalistic thoughts. Her experience may have been different had an understanding of HPV treatment been present. Therefore, consideration of gaps in knowledge, transmission, health consequences and factors associated with HPV as identified in this case are essential for the development of interventions and improvement in adherence to follow-up among women with abnormal pap smears. ${ }^{25}$ Both men and women require awareness of HPV risk factors. ${ }^{4}$ Many women and men do not know about HPV as a STI, its risk factors and procedures for early detection of cervical cancer, especially the pap test, as a preventive method for early detection of this disease. ${ }^{25}$

Community based interventions are indicated for health promotion concerning HPV. ${ }^{7}$ Information alone however may not be sufficient for behavioral change. ${ }^{26}$ Real stories of women who are going through the same situation, as described in this case study may promote a better understanding of HPV, its progression and importance of treatment adherence. ${ }^{25}$ As this case implies, it is prudent to address preventive measures for women of all ages and to raise awareness of the importance of attending cytological screening upon becoming sexually active even though asymptomatic.

It is important to note that in Mexico, health personnel are expected to offer screening to all women between 25-64 years of age, especially those with risk factors. The screening for cervical cancer, however may be provided to anyone who requests screening regardless of age. This was the situation for Ms.J who was 19 years of age at the time of testing; she voluntarily sought testing although not within the recommended age for screening for cervical cancer. The guidelines of the United States Preventive Services Task Force (USPSTF) and the American Cancer Society (ACS) ${ }^{27}$ recommend testing every three years for women ages 21-65; routine cervical cancer screening for women under 21 and over 65 is not recommended. In the environment of the Balance of Harms and Benefits, the USPSTF establishes that the screening women ages 21 to 65 years every 3 years with cytology provides a reasonable balance between benefits and harms; screening 
with cytology more often than every 3 years confers little additional benefit, with large increases in harms. Although there are rules and guidelines that health professionals should follow, if a woman decides to obtain screening before the recommended age, this service is not denied in Mexico as in Ms. J's case. Ms. J's decision to obtain screening was an outcome of her perceived risk for HPV related to her sexual behavior.

Implementation of health promotion programs to vulnerable populations with personalized attention for women who are carriers of HPV and their partners may increase awareness of the disease. Strategies considered important include:

i. Importance of proper condom use

ii. Stability in the sexual partner (monogamy)

iii. Control and monitoring by cervical cytology in women and peniscopy in men

iv. Vaccination

v. Psychological support with the goal of eliminating fatalistic thoughts and achieving coping with the disease

vi. Self-efficacy for decision-making and skills

vii. Adoption of protective behaviors for couples who have HPV to prevent the development of cancer. Previous studies in which these programs have been implemented bring attention to this problem, but unfortunately do not include the couple..$^{7,28-30}$ These programs, through inclusion of the couple, would potentially contribute to a higher reduction in the morbidity and mortality of HPV.

Colon et al. ${ }^{31}$ understood the need to assess awareness and knowledge of HPV among men. Their assessment found none of the men had been vaccinated and awareness of the importance of vaccination was low. While the vaccination program in Mexico is aimed at females aged nine years and older who have not initiated sex, the Advisory Committee on Immunization Practices ${ }^{11}$ has recommended young men and women have three doses of the HPV vaccine. Our case study highlights the importance of a HPV vaccination program for men in Mexico as they are often asymptomatic carriers of the virus or the principal agents of transmission.

This case study also highlights the need for interventions for adolescents prior to onset of sexual debut. It would be important for adolescent populations to receive counseling about HPV by trained professionals to raise awareness about measures to increase prevention and protection, partner communication and control of HPV. This information may be disseminated through the delivery of brochures or the placement of posters and videos in media or social networks frequented by adolescents. Design of a self-assessment including key questions for assessment of HPV risk, decision-making and resources for guidance and adherence to HPV prevention measures and cervical cancer is indicated. Among those impacted by HPV, a manual designed to provide information about coping in situations in which the women or man is a carrier of the virus would be helpful to dispel common myths about HPV. This information would be useful to eliminate fatalistic thoughts such as experienced in this case study, and raise awareness regarding the implications of having HPV thereby promoting prevention and attachment behaviors.

A need for psychological support was identified in this case study. This is a consideration as a diagnosis of HPV generates a wide range of strong emotional responses such as denial, stoicism, disgust, shame, anger, self-blame, fear, betrayal, depression, low self-esteem, and decreased sexual desire. These emotions have been associated with poor health education among populations and poor access to health care. ${ }^{32}$ Health care providers' contribution to these individuals care necessarily includes emotional support and counseling to achieve attachment within intimate relationships in addition to monitoring of timely treatment. ${ }^{21}$

\section{Conclusion}

HPV infection is a public health priority due to the magnitude of the emotional and physical burden of the disease. This case report identified multiple emotional or psychological aspects of a HPV diagnosis in women and its potential impact on interpersonal relationships. Knowledge was identified as one of the most important components of decision making and is closely related to prevention, control, stigma, generation of fatalistic thoughts, cultural perspectives, protective behavior of HPV and cervical cancer. Personal, social and emotional aspects of perceived risk of HPV transmission among women with HPV must be considered as these potentially interfere with the ability to cope and initiate or complete treatment as prescribed by health care providers. These aspects may also impact awareness of the importance of protective behavior and participation of partners in this process. This case study elucidates the need for education about reproductive health, the HPV vaccine and Pathophysiology of HPV, its transmission and prevention. It also exemplifies the importance of inclusion of men as well as women in the programs as often the focus is primarily on women. Utilization of case studies as a component of these programs may enhance application of this knowledge. The present case study supports the implementation of protocols in educational institutions and achieve a reduction of HPV morbidity rates, provide guidance on the care of sexuality from an early age, vaccination campaigns achieving complete schemes, follow-up of women identified through the control gynecological HPV and individual or couple psychological therapies for coping with the disease. Currently there is a program called Responsible Sexuality in social networks where scientific scientists offer guidance to the entire population interested in their sexual health as well as low cost gynecological control programs to contribute to the economy of the country.

\section{Acknowledgements}

Thank you to the woman involved in the case study, thank you for your confidence.

\section{Conflict of interest}

The authors report no conflicts of interest.

\section{Patient consent form}

The participant has signed the informed consent where she agrees to participate in the present case report.

\section{References}

1. Organización mundial de la salud; 2016.

2. Instituto nacional de cáncer (INC); 2014

3. Center for Disease Control and Prevention: Recommendations on the use of quadrivalent human papillomavirus vaccine in males. Advisory committee on immunization practices. Morbidity and Mortality Weekly Report. 2011;60:1705-1708. 
4. Castanedo CIM, Escaño CV, Rebola GP. Enfermería y el virus del Papiloma Humano, a propósito de un caso. Enfermería Docente. 2013;100:23-27.

5. IH Frazer, JT Cox, EJ Mayeaux, et al. Advances in prevention of cervical cancer and other human papillomavirus-related diseases. Pediatr Infect Dis J. 2006;25(2 supply):S65-81.

6. Machado MDFAS, Araújo MAL, Mendonça LMD, et al. Comportamento sexual de mulheres com papiloma vírus humano em serviços de referência de Fortaleza, Ceará. Revista Brasileira em Promoção da Saúde. 2010;23(1).

7. Givaudan M, Leenen I, Pick S, et al. Enhancement of underused cervical cancer prevention services in rural Oaxaca, Mexico. Rev Panam Salud Publica. 2008;23(2):135-143.

8. Eggleston KS, Coker AL, Das IP, et al. Understanding barriers for adherence to follow-up care for abnormal pap tests. Journal of Women's Health. 2007;16(3):311-330.

9. Lazcano-Ponce EC, Nájera-Aguilar P, Buiatti E, et al. The cervical cancer screening program in Mexico: problems with access and coverage. Cancer Causes Control. 1997;8(5):698-704.

10. Luna-Blanco MA, Sánchez-Ramírez G. Posibilidades sociales de prevención de la infección por virus del papiloma humano y de cáncer cervicouterino en San Cristóbal de Las Casas, Chiapas, México, LiminamR. 2014;12(2):67-80.

11. Center for Disease Control and Prevention. Quadrivalent human papillomavirus vaccine recommendations of the Advisory Committee on Immunization Practices. $A C I P$. 2007;56(RR02):1-24.

12. Rocha A, Bologna R, Rocha C. Virus del papiloma humano y el cáncer de cabeza y cuello: revisión de la literatura desde México y Colombia. Universitas Odontológica. 2012;30(67):149-157.

13. Gilmore N, Somerville MA. Stigmatization, scapegoating and discrimination in sexually transmitted diseases: Overcoming 'them' and 'us'. Soc Sci Med. 1994;39(9):1339-1358.

14. Wright M, Rodway M. Sexually transmitted diseases: Psychosocial parameters and implications for social work practice. Journal of Social Work \& Human Sexuality. 1998;6:21-35.

15. New Zealand Herpes Foundation. Guidelines for the management of genital herpes in New Zealand. Sexually Transmitted Infection Education Foundation. 11th ed. New Zealand: Springer; 2014.

16. Arellano Gálvez MDC, Castro Vásquez MDC. El estigma en mujeres diagnosticadas con VPH, displasia y cáncer cervicouterino en Hermosillo, Sonora. Estudios sociales. 2013;21(42):259-278.

17. Fernández ME, McCurdy SA, Arvey SR, et al. HPV knowledge, attitudes, and cultural beliefs among Hispanic men and women living on the TexasMexico Border. Ethnicity Health. 2009;14(6):607-624.

18. Hirsch JS, Higgins J, Bentley ME, et al. The social constructions of sexuality: marital infidelity and sexually transmitted disease-HIV risk in a Mexican migrant community. Am J Public Health. 2002;92(8):12271237.
19. Waller J, Marlow LA, Wardle J. The association between knowledge of HPV and feelings of stigma, shame and anxiety. Sex Transm Infect. 2007;83(2):155-159.

20. Kosenko KA, Hurley RJ, Harvey JA. Sources of the uncertainty experienced by women with HPV. Qual Health Res. 2012;22(4):534 545.

21. Holland AA. Have I HPV. Does that mean that my husband cheated on me? Answering women's questions about HPV. The Association of Women's Health, Obstetric and Neonatal Nurses. 2013;42:1.

22. Cosse I. Cultura y sexualidad en la Argentina de los sesenta: usos y resignificaciones de la experiencia transnacional. Estudios interdisciplinarios de América Latina y el Caribe. 2014;17:1.

23. Wigfall L, Rawls A, Sebastian N, et al. HPV high risk and protective behaviors: The effects of religious affiliation. $J$ Relig Health 2012;51(4):1325-1336.

24. Fish LJ, Moorman PG, Wordlaw-Stintson L, et al. Factors associated with adherence to follow-up colposcopy. Am J Health Educ. 2013;44(66):293298

25. Bellinger JD, Millegan W, Abdalla AE. "I'm not ashamed to talk on it!' African-American women's decisions about cervical cancer prevention and control in South Carolina. Women's Health Issues. 2015;25(2):120127.

26. Berkowitz Z, Saraiya M, Benard V, et al. Common abnormal results of pap and human papillomavirus cotesting: what physicians are recommending for management. Obstet Gynecol. 2010;116(6):1332-1340.

27. Screening for Cervical Cancer: Clinical summary of U.S. Preventive services task force recommendation AHRQ publication No. 11-05156EF-3; 2012.

28. Meza MP, Mancilla J, Morales F, et al. Adaptación psicológica en mujeres con infección por virus de papiloma humano. Perinatología y Reproducción Humana. 2011;25(1):17-22.

29. Daley EM, Perrin KKM, Vamos C, et al. HPV knowledge among HPV+ women. Am J Health Behav. 2008;32:477-487.

30. Saenz-Soto NE, Benavides-Torres RA, Champion JD. Attachment and associated sexual health behaviors of heterosexual mexican housewives. Issues Ment Health Nurs. 2015;36(4):258-265.

31. Colón-López V, Ortiz AP, Del Toro-Mejías LM, et al. Awareness and knowledge of human papillomavirus infection among high-risk men of Hispanic origin attending a sexually transmitted infection clinic. $B M C$ Infectious . 2012;12:346.

32. Concha X, Urrutia T, Riquelme G. Creencias y virus papiloma humano. Revista chilena de obstetriciay ginecología. 2012;77(2):87-92. 